\title{
Climate Change at the Very End of a Warm Stage: First Results From the Last Glacial Inception at 117,000 yr BP
}

\author{
F. Sirocko ${ }^{1}$, U. Cubasch ${ }^{2}$, F. KaspaR ${ }^{3}$, H. von Storch ${ }^{4}$, M. Widmann ${ }^{4}$, T. Litt $^{5}$, N. Kühl ${ }^{5}$, A. Mangini ${ }^{6}$, H.-J. Pachur ${ }^{7}$, M. Claussen ${ }^{8}$, C. \\ Kubatzki $^{8}$, F.W. Junge ${ }^{9}$, T. BötTGeR ${ }^{10}$, M. KRbetscheK ${ }^{11}$ and D. Degering ${ }^{11}$ \\ ${ }^{1}$ Institute of Geology, Johannes-Gutenberg Universität, Johann-Joachim-Becher Weg 21, 55099 Mainz; sirocko@mail.uni-mainz.de \\ Institute of Meteorology, FU Berlin, Carl-Heinrich-Becker Weg 6-10, 12165 Berlin \\ ${ }^{3}$ Max Planck Institute for Meteorology, Bundesstr. 55, 20146 Hamburg \\ ${ }^{4}$ Institute for Coastal Research, GKSS Research Center, Max-Planck-Str. 1, 21502 Geesthacht \\ ${ }^{5}$ Institute of Paleontology, Rheinische Friedrich-Wilhelm-Universität Bonn, Nussallee 8, 53115 Bonn \\ ${ }^{6}$ Heidelberg Academy of Sciences, Im Neuenheimer Feld 229, 69120 Heidelberg \\ ${ }^{7}$ Departement of Earth Sciences, Free University of Berlin, Malteserstr. 74-100, 12249 Berlin \\ ${ }^{8}$ Potsdam Institute for Climate Impact Research, Telegraphenberg, 14473 Potsdam \\ ${ }^{9}$ Saxon Academy of Sciences in Leipzig, Karl-Tauchnitz-Str. 1, 04107 Leipzig \\ 10UFZ-Sektion Hydrogeologie, Theodor-Lieser Str. 4, 06120 Halle \\ ${ }^{11}$ Saxon Academy of Sciences, Quaternary Geochronology Section at TU Bergakademie Freiberg, 09596 Freiberg/Sachsen, Germany
}

\section{Introduction and Objectives}

The ongoing warm stage, the Holocene, has lasted until now about 11,500 years. Past interglacials occurred every 100,000 years and had durations between 7,000 and 17,000 years, estimated from the Vostok ice core and annual-layercounted varved lake sediments in northern Germany. The objectives for the DEKLIM project "Climate change at the very end of a warm stage" are to:

a) determine the length of past interglacials in Europe with high precision by varve counting of lake sediments,

b) reconstruct environmental change at the end of an interglacial by pollen analysis,

c) date interglacials by U/Th and luminescence techniques,

d) quantify the temperature change at the very end of past interglacials with both proxy and model data,

e) use the models to detect the physical causes that determine the end of an interglacial. Understanding of the warm to cold transitions of the last 500,000 years should provide background information on the processes that would control the natural climate evolution at the end of the Holocene.

\section{Project Structure}

The project is a bundle of nine individual proposals.

\section{High Resolution Proxy Records}

- Mainz:The ELSA-Project (Eifel Laminated Sediment Archive) has drilled 1,200 m of laminated cores (up to $155 \mathrm{~m}$ length) from 40 dry maars of the Eifel in western Germany during the last three years. $70 \%$ of the sediments are laminated, most of them in annual layers. The maar cores cover the entire time from 5-140 ka. Varved sediments from the older interglacials MIS 7, 9, and 11 have been drilled at several sites in northern Germany. The Mainz team (Frank Sirocko, KIemens Seelos, Marcus Diehl, Katja Schaber) use thin sections for varve counting, grain-size for loess quantification and pollen analysis for environmental reconstruction.

- Leipzig:Tatjana Böttger, Frank Junge and Stefan Knetsch study Eemian sediment sections in several open cast lignite mines in Germany and Russia. The number of these unique archives decreases from year to year due to economical changes. It is the purpose of their project to document these well dated records, to reconstruct the past environment by pollen and isotope analysis, and to extend the regional coverage of sites further towards the east, which is done in close cooperation with Elena Novenko and Andrei Velichko, Moscow.

- Berlin: Hans-Joachim Pachur, Bernd Wünnemann, Kai Hartmann and Norbert Altmann analyze a 230 m-long (MIS 2 to at least MIS 13) laminated lake sediment core from the Gaxun Nur basin to detect the history of lake evolution, flash floods and eolian deposition in Central Asia, and extend the transect of cores from Europe through Russia, well into Asia.
Dating

- Heidelberg: Augusto Mangini, Steffen Holzkämper and Denis Scholz provide high precision dates from stalagmites and corals for the onset and end of MIS 5 and 7 in Europe and Arabia. These absolute dates are to be combined with the floating chronologies from the proxy records above. In addition, $\delta^{18} \mathrm{O}$ studies of the stalagmites give a temperature and humidity related signal.

- Freiberg: Matthias Krbetschek and Detlev Degering provide luminescence dates for the above different proxy records and are developing a new radioluminescence dating technique, which will be applied for the MIS 7-9 records of the project.

\section{Quantitative Paleoclimate Reconstruc- tion and Modeling}

- Bonn:Thomas Litt and Norbert Kühl developed a new proxy-temperature transfer method using probability density functions. This method will be applied to all the pollen records of this project and serves to obtain quantitative paleoclimate information, which will be compared with the model results. The reconstructed temperatures of time slices over Europe, as well as first time-series are available now and under discussion by the modeling groups.

- Berlin: Ulrich Cubasch and Frank Kaspar study the last glacial inception (MIS 5e-5d transition) with the coupled ocean atmosphere model ECHO-G for the time slices $125 \mathrm{ka}$ and $115 \mathrm{ka}$ when $\mathrm{CO}_{2}$ content was similar but seasonal insolation very different. 


\section{Science Highlights: DEKLIM}

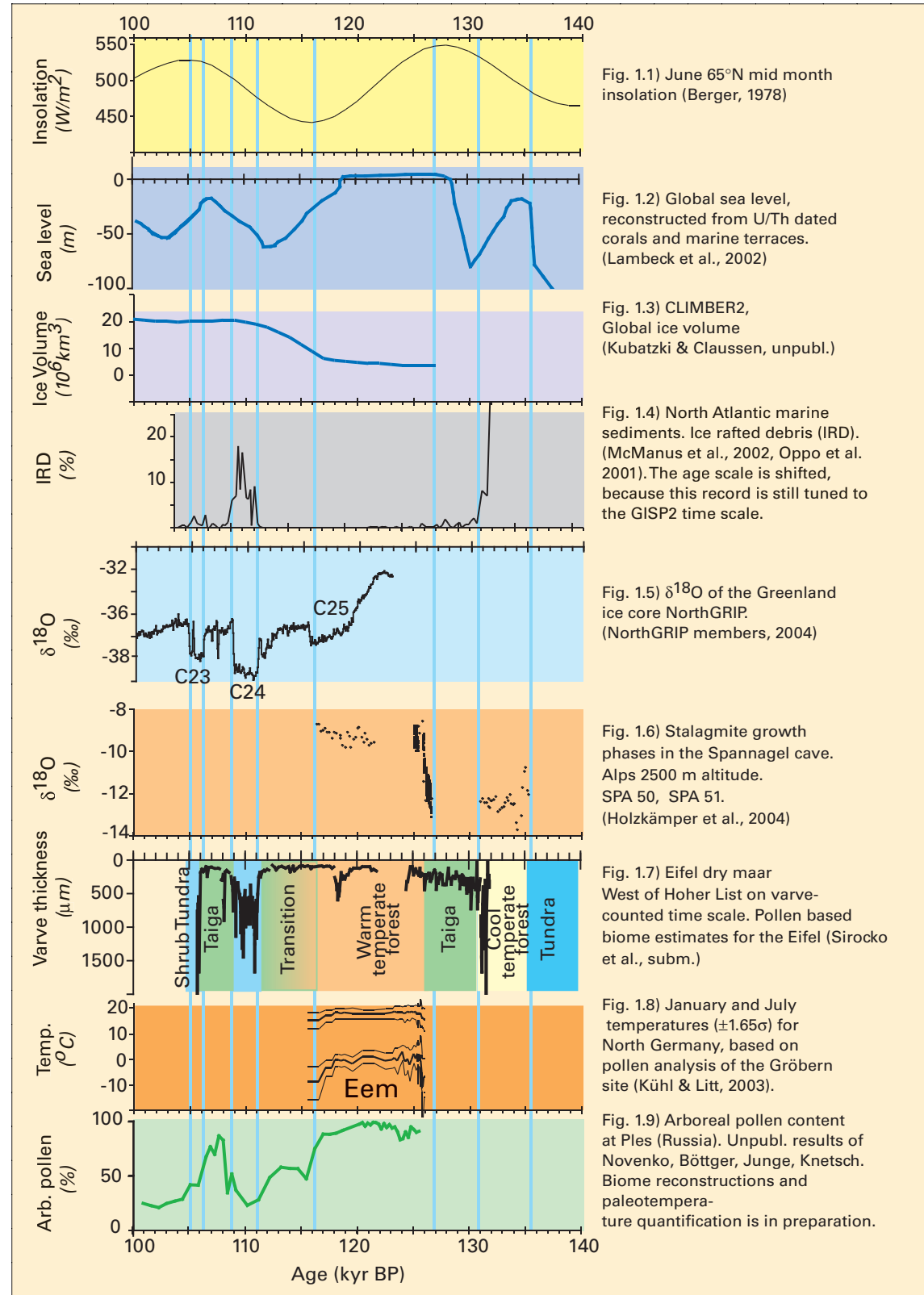

Fig. 1: The time 100,000 - 140,000 ka in published records and new DEKLIM records.

- Geesthacht: Martin Widmann and Hans von Storch are developing a technique for upscaling and nudging to perform assimilation experiments with coupled ocean atmosphere model ECHO-G, in particular to detect the role of the NAO for the European climate during the Eemian; see also the DATUN project.

- Potsdam: Martin Claussen and Claudia Kubatzki use the CLIMBER2 earth-system model of intermediate complexity to produce long time transient runs, which can be directly compared to long proxy records, even over hundreds of thousands of years.

All modeling activities closely cooperate with ClimCyc (see page ice rafted debris in the North Atlantic (i.e. decay of a continental ice sheet) appeared during $\mathrm{C} 24$, i.e. 4,000 years after the $115 \mathrm{ka}$ insolation minimum and after 6,000 years of continuous ice sheet growth and $50 \mathrm{~m}$ sea level lowering since the last glacial inception (LGI) at $117 \mathrm{ka}$ (Fig. 1.4). The new Greenland ice core NorthGRIP shows the surge events C25, C24, C23 very nicely and puts them on a layer counted time scale (Fig. 1.5). Another remarkable feature of the NorthGRIP $\delta^{18} \mathrm{O}$ is the beginning of a smooth Greenland temperature decrease starting already at $122 \mathrm{ka}$, thus well before the LGI.

Results of the DEKLIM-EEM Project specify the climate and environmental conditions on the European continent. Most results are not published yet because the last DEKLIM field campaigns (e.g. drilling the Eifel dry maars) are in summer 2004, thus Fig. 2 presents the state of the art.

$\mathrm{U} / \mathrm{Th}$ dating of first stalagmite growth in the alpine Spannagel cave (Fig. 1.6) gives an age of 135 ka for the onset ofTermination II on the European continent, consistent with the rise of global sea level. A climatic deterioration is indicated from 130-126 ka before the onset of the Eemian. The Spannagel cave is at $2,500 \mathrm{~m}$ altitude with a modern annual temperature of $+1^{\circ} \mathrm{C}$. Thus, a reduction of the annual temperature at 2,500 m by more than $1^{\circ} \mathrm{C}$ is enough to terminate stalagmite growth, which has apparently happened twice. The final growth of this stalagmite, representing the end of the Eemian, is dated at 116 ka (Holzkämper et al. 2004).

The record from the Eifel dry maar west of Hoher List (HL2, Fig. 1.7) extends from $30-140$ ka (Sirocko et al., subm.) and we present here only the varve thickness data for 100-140 ka. There are two sections where varve counting is impossible in this time interval and thus, the floating varve chronology takes the beginning of $\mathrm{C} 24$ as the start point, because this event is well dated in the NorthGRIP record. A second fixpoint is the beginning of the Eemian at $126 \mathrm{ka}$ in the stalagmite growth record, which should coincide with the first appearance of thermophilous Eemian trees in 
central Europe (see also Fig. 1.6). The paleotemperature calculations of Kühl and Litt (2003) are based on probability density functions and determine summer and winter temperature. The method is already applied to the pollen records of the site of Gröbern, where we observe a reduction of about $3^{\circ}$ for summer and about $10^{\circ}$ for the winter temperatures at the end of the Eemian (Fig. 1.8). The Eemian Gröbern section has a duration of approximately 11,000 years, based on the varve counts of the classical Bispingen site (Müller, 1974), a value that fits nicely into the new absolute dates from the stalagmites. A discrepancy exists between the classical varve counts and pollen succession and the results from the Eifel. Short taiga phases at the end and beginning of the Eemian in the Bispingen record are included in the 11,000 year duration estimated by Müller (1974) - the taiga phase before the Eemian onset and the transitional time at the end of the Eemian in the varve counted Eifel record result in a significantly longer duration than 11,000 years. A part of this discrepancy could be caused by locally different durations of the transitional vegetation between North Germany and the Eifel.

Pollen records from East Germany and Russia also document the typical Eemian succession of trees (Fig. 1.9) but chronologies after the LGI are difficult to obtain. The pdf-transfer method will be applied to all pollen records from the Eifel to central Russia to detect the temperature gradient from the North Atlantic Ocean far into the Eurasian continent; the most important question is the continental equivalent for the C23-C25 cooling events. The transcontinental profile will finally reach into central Asia, where a long laminated record from the Gaxun Nor basis is studied by our Berlin group (not presented yet). These continental-wide maps of paleotemperature evolution are compared with results from model experiments.

The most encouraging result from the model data comparison (both time transient and equilibrium runs) is the observation that the glacial in-

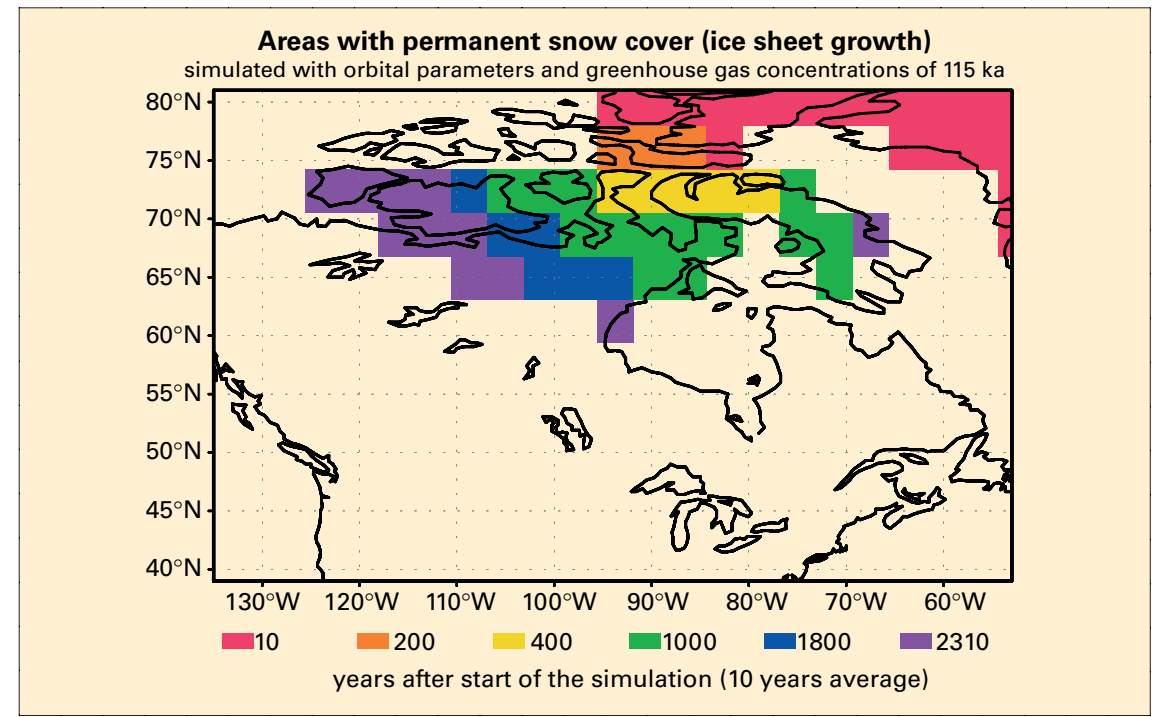

Fig. 2: Expansion of permanent snow-covered areas in an ECHO-G simulation for $115 \mathrm{ka}$ Resolution: atmosphere $3.75^{\circ}$, ocean $2.8^{\circ}$, orbital parameters and $\mathrm{CO}_{2}$ are kept at constant values of $115 \mathrm{ka}$.

ception in proxy records and models occurs almost at the same time (117 ka) at the beginning of the global sealevel lowering. Both CLIMBER-2 (Fig. 1.3) and ECHO-G model results (Fig. 2) show that insolation change alone is sufficient to cause North American ice sheet growth at a threshold near $450 \mathrm{~W} / \mathrm{m}^{2}$, which is just $40 \mathrm{~W} / \mathrm{m}^{2}$ below our modern summer insolation at $65^{\circ} \mathrm{N}$. The last glacial inception (LGI) between 116 and $118 \mathrm{ka}$ is paralleled by a transition from warm temperate forest to taiga vegetation in the Eifel. A similar transition must have occurred in central Europe, however, possibly with large local variability. The most severe cold in Europe, however, occurred at about $111 \mathrm{ka}$, when the Eifel was dominated by shrub tundra, coinciding with a time when the North Atlantic was covered by the floating ice of the $\mathrm{C} 24$ surge, 6,000 years after the LGI and continuous ice sheet growth.

The synthesis from all nine partners of the DEKLIM project "Climate Change at the very end of a warm stage" highlights the principal role of insolation changes as a pace maker of climate change. The critical point is the threshold for a glacial inception. Insolation, albedo/vegetation, atmospheric greenhouse gas concentrations, volcanic and desert dust are regarded as the major variables for calculation of the threshold. Abrupt and strong climate change synchronous in the ocean, on land, and worldwide teleconnected, however, occurs mostly during cold events, when continental ice sheets have grown high enough to produce surges that cool sea surface temperature, effect the thermohaline circulation and change the continental environment by meltwater and vegetation feedbacks. The critical question for the end of the Holocene is thus, if/ when we will reach the threshold of a glacial inception, and to what extent anthropogenic activity can modify the natural climate evolution.

\section{REFERENCES}

Berger, A.L., 1978: Long term variations of caloric solar radiation resulting from the earth's orbital elements, Quaternary Research 9, 139-167.

Holzkämper, S., Mangini, A., Spötl, C. and Mudelsee, M., in press.: Timing and progression of the Last Interglacial derived from a high alpine stalagmite, Geophysical Research Letters 31, L07201, doi: 10.1029/2003GL019112

Kühl, N., and Litt, T., 2003: Quantitative time series reconstruction of Eemian temperature at three European sites using pollen data. Vegetation History and Archaeobotany 12, 205-214

Lambeck, K. and T. M. Esat, et al., 2002: Links between climate and sea levels for the past three million years. Nature 419, 199-206.

McManus, J. F., Oppo, D. W., Keigwin, L. D., Cullen J. L., and Bond, G. C., 2002: Thermohaline circulation and prolonged interglacial warmth in the North Atlantic. Quaternary Research 58, 17-21.

Müller, H., 1974: Pollenanalytische Untersuchungen und Jahresschichtenzählungen an der Eem-zeitlichen Kieselgur von Bispingen/Luhe. Geologisches Jahrbuch A21, 149-169.

North Greenland Ice Core Project members, 2004: High-resolution record of Northern Hemisphere climate extending into the last interglacial period, Nature, 9th of September.

Sirocko et al., submitted: The end of the last interglacial in central Europe. Science. 